\title{
Digital Barriers and Individual Coping Behaviors in Distance Education During COVID-19
}

Isabel Gan, Thomas Jefferson High School for Science and Technology, USA

Rui Sun, California State University, Dominguez Hills, USA

(iD https://orcid.org/0000-0002-2518-7460

\begin{abstract}
Information and communication technologies (ICT) have played a pivotal role in facilitating knowledge acquisition and enabling distance education. Yet, knowledge about digital divide in distance education remains limited. This study examines digital barriers that underserved students face in distance education and their coping behaviors during the coronavirus pandemic (COVID-19). Informed by distance education and digital divide literature, this study uses qualitative research method to analyze survey data collected from 206 college students in a four-year public university in the United States. Results revealed five major digital barriers and showed that the distribution of these digital barriers varied by student demographic background and socioeconomic status. Further analysis of respondents' narratives revealed three coping behaviors, including improvising, building technical assets, and building social assets. Practical implications are provided to educators and policymakers to invest in ICT and implement equity-minded teaching practices to enhance digital inclusion.
\end{abstract}

\section{KEYWORDS}

Coping, Digital Divide, Digital Skills, First-Generation Students, Higher Education, Minority Students, Qualitative, Technology Use

\section{INTRODUCTION}

Information and communication technologies (ICT) have played a pivotal role in facilitating knowledge acquisition and sharing in organizations (Alavi \& Leidner, 2001). Traditionally, knowledge has been considered a pyramid on four building blocks including data, information, knowledge, and wisdom (Jennex \& Bartczak, 2013). Advancements in ICT have motivated knowledge management (KM) scholars to revise this pyramid. For example, Jennex (2017) added a new component - big data, IoT (Internet of Things), and business intelligence - which "reflects the way technology innovation is radically addressing societal and organizational needs for more data and more actionable intelligence" (p. 75).

In higher education, the advancements of Internet and ICT have enabled distance education, where teaching and learning take place online through network technologies. Yet, educational 
institutions continue to face challenges associated with technical expertise and infrastructure in achieving effective learning outcomes (Cho \& Berge, 2002). With the widespread impact of the coronavirus pandemic (COVID-19) and the in-person classes moved to alternative modes (i.e., online, distance learning), educational institutions face a new normal characterized by the omnipresent and increasing reliance on ICT. With more than 1.2 billion students in 186 countries affected by school closures in spring 2020 due to COVID-19 (Li \& Lalani, 2020), the challenges in distance education become more evident.

Among the populations of students switching to online learning during COVID-19, underserved minority students are experiencing a higher level of difficulty and a lower level of technology readiness (Frazier, 2020). An underserved student population typically includes low-income students, racial and ethnic minority students, and first-generation college students (FGCS). In particular, with parents having no post-secondary education experience, FGCS were found at high risk of attrition during freshman year and suffering from low graduation rate (Lauff \& Ingles, 2015). Higher education institutions, particularly four-year institutions, have struggled to develop successful strategies to mitigate the gaps in the college persistence of FGCS (Schwartz et al., 2018). Lacking technical resources and digital skills may leave FGCS feeling overwhelmed in the online learning environment during COVID-19. Therefore, understanding their barriers in online learning has become an important step to achieving digital inclusion in distance education.

Following previous research (Notley, 2009; Sen, 2000), we define digital inclusion in distance education as utilization of ICT to participate in learning activities, measured by the level of ICT access and proficiency. Digital inclusion is closely related to digital divide, which focuses on the gap in technology access and use. Such gap remains a concern to many countries. A study of 28 European Union countries suggests that digital divide within each member country exists, even for those European countries that are outperforming their counterparts in terms of digital development (Cruz-Jesus et al., 2016). In the United States, although many aspects of the digital divide have narrowed over time, the digital lives of lower- and higher-income Americans remain drastically different. According to a recent report, more than $40 \%$ of adults with annual household incomes below $\$ 30,000$ do not have broadband services or a traditional computer and roughly $30 \%$ do not own a smartphone. In comparison, these technologies are nearly ubiquitous among adults in households earning $\$ 100,000$ or more annually (Anderson \& Kumar, 2019). Prior to COVID-19, those without Internet access used to fill the gap by using free Internet in public places. During COVID-19, the stay-at-home orders and social distancing mandate make it virtually and physically impossible for students using these free resources, at least in the short term (Lee, 2020).

As the pandemic evolves, it is important for higher education institutions to understand the barriers to online learning, especially digital barriers experienced by students, in order to adapt to students' needs and support them in achieving academic continuity during crises. Thus, this study examines digital divide and digital barriers in distance education in the context of COVID-19 by addressing two questions: (1) What digital barriers do underserved students face in distance education during COVID-19? (2) How do underserved students cope with these digital barriers?

To achieve our research objectives, we review literature on distance education and digital divide to inform our data analysis and interpretation of results. Using data collected from 206 survey respondents at a four-year public university in the United States, this study revealed five major digital barriers and found that the distribution of these barriers varied by the ethnic background and economic status of the students. We also discovered three coping strategies used by the survey respondents. The study highlights the urgency for educational institutions to better understand the learning needs of economically and ethnically diverse students in order to help them engage in distance education and achieve their academic goals. Our findings could make an immediate impact by providing practical implications and guidelines to educational institutions. 


\section{LITERATURE REVIEW}

This section reviews literature on distance education and digital divide. Specifically, we discuss the benefits and barriers of distance education, and the influencing factors of digital divide.

\section{Distance Education}

Distance education is one of the most powerful responses to the growing need for education in today's digital society (Zhang et al, 2004). Following Zhang et al. (2004), we define distance education (or "online education") as involving teaching and learning online through network technologies. Distance education provides numerous benefits to learners. For example, through computer-mediated communications, students have the flexibility to perform learning activities at their preferred time, location, and pace in distance education. In reviewing relevant literatures, we focused on the barriers to distance education from the learner's perspective.

Distance education has encountered many barriers. Muilenburg and Berge (2001) identified and categorized the barriers into 10 clusters, including technical expertise, administrative structure, evaluation/effectiveness, organizational change, social interaction and quality, student support services, threatened by technology, access, faulty compensation and time, and legal issues. Using the 10 clusters of barriers as the categorizing framework, Cho and Berge (2002) studied 32 cases of leading organizations in distance education. Their study has shown technical expertise as the dominant cluster of barriers in distance education. Technical expertise consists of technology infrastructure and technical support, both closely linked to other barriers like user access, student support, and learning quality. From learners' viewpoint, Safford and Stinton (2016) examined online adult learners' difficulties in distance education and found that they had underdeveloped skills for locating, storing, and retrieving information digitally.

To overcome barriers in distance education, prior research offered useful recommendations on changing organizational structure or improving organizational effectiveness. However, the focus of these research was on organizations, not on learners. The experiences of online learners and their technical skills are also key to their online learning success. Kim et al. (2008) highlighted that students' apprehension about using ICT and "fast-changing tech" are the most significant issues to addressing distance education (p. 14). For online course design, Safford and Stinton (2016) suggested providing opportunities for students to become familiar with online tools at the beginning of a course, followed by later requirements to use these tools to gain skills and knowledge.

In summary, prior studies have suggested the importance of ICT resources and digital skills for achieving student success in distance education. However, it is not clear if online students from underserved communities are equitably equipped in educational technology and digital skills as their peers.

\section{Digital Divide and Digital Inclusion}

According to the U.S. National Telecommunications and Information Administration (NTIA, 1999), digital divide refers to "the divide between those with access to new technologies and those without" (xiii). This conceptualization reflects socioeconomic inequality defined by having access to computers and Internet or not. Starting in the 2000s, researchers have pivoted to user abilities and skills, Internet usage, and the access complexity. They argued that digital divide cannot be simply measured by having physical access to computers and Internet; rather, it should be measured by how digital technologies are used in people's daily life (Van Dijk, 2006). Moreover, a country's Internet connection rate reaching saturation does not mean that the digital divide problem would be solved. A recent study suggests that material access of technologies remains a problem in one of the richest and most technologically advanced countries in the world (Van Deursen \& Van Dijk, 2019).

Although there is no unified definition of digital divide, the concept generally highlights four areas of importance: access, skills, types of usage, and attitudes (Jones et al., 2009; Van Deursen \& 
Van Dijk, 2019). While physical access gap has diminished, other gaps still exist. One area is the differential possession of digital skills. Digital skills are partly about managing the technology and different skills related to content and activities (Van Deursen \& Van Dijk, 2008). Gender is also a crucial predictor. Jones et al. (2009) found that males spend more time on leisure activities than females, including listening to and downloading music as well as watching and downloading videos. However, these studies focused on the Internet technology in daily life. Our knowledge about student use of academic technologies remains limited.

Compared to digital divide, digital inclusion is a broader concept concerning individual ability to access and use ICT to improve the work and life of the disadvantaged population. Notley (2009) suggests that ICT access and proficiency are critical for high risk and underserved populations to improve their lives. Similarly, a RAND report states, "The digital world is increasingly penetrating the education and skills domain, with technology gradually being used to deliver education, knowledge and skills in new and innovative ways" (Grand-Clement, 2017, p. 2). With the widespread impact of COVID-19 on education, students' proficiency in ICT has become essential to their performance in online learning. Therefore, this study provides an in-depth analysis of the digital barriers experienced by underserved college students.

\section{METHOD}

We conducted a qualitative study to understand how college students experienced and adapted to online learning modality during COVID-19 in spring 2020. Our research objective is to examine how human actors (underserved college students) made sense of their participation in the online learning environment rather than to hypothesize or test cause-and-effect relationships. Informed by earlier theorizing and by our empirical study, our goal is to develop an analytical generalization regarding digital barriers in distance education. We followed the qualitative research method proposed by Miles and Huberman (1996) to perform the data analysis.

The data reported in this study is part of a large project examining educational resilience and learning barriers (not only digital barrier) in a four-year urban, public university in the United States. The university is known for serving an economically and ethnically diverse student population, including $60 \%$ of students being Hispanic or Latino, 15\% Black or African American, 11\% White, $11 \%$ Asian, and 3\% others. In addition, about half of the students are FGCS, and approximately $60 \%$ are eligible for the Federal Pell grant, a need-based financial aid program in the U.S. Given the diversity of its student body, this university is an ideal research site for us to study student online learning experience and digital barriers during COVID-19.

Three modalities of classes are normally offered by this university: in-person (on-campus), online, and hybrid. In-person classes enroll majority of the students. The learning platform "Blackboard" was utilized as the main web-based course management system. Due to COVID-19, the university suspended all on-campus classes in March 2020 and started "alternative instruction" (online, distance learning).

The survey data was collected via SurveyMonkey in late March to early April of 2020. It included open-ended questions asking about students' views surrounding technology readiness, problems associated with online learning, concerns about COVID-19, learning needs, and demographic and socio-economic background (see the questionnaire in Appendix). A total of 206 students completed the survey, resulting in a response rate of $45.8 \%$ (out of 450 students who received the survey). It is a convenience sample collected from several classes with instructors' permissions.

Among the 206 respondents, 52.4\% are female, $66.5 \%$ are employed full-time or part-time, and $61.7 \%$ reported themselves as FGCS. About $83 \%$ of respondents are junior or senior undergraduates and $7 \%$ are graduate students. About $60 \%$ of the respondents come from families with annual household income less than $\$ 50,000$. Moreover, ethnic minority students accounted for $86.4 \%$ of the sample, including 59.7\% Hispanic/Latino, 15\% Asian or Pacific Islander, and 11.7\% Black or African 
Americans. This is consistent with the university-wide data. Table 1 summarizes the distribution of the study participants by their demographic and socio-economic background.

The coding of the barriers was informed by prior research, including technical problems (Muilenburg \& Berge, 2005) and skill deficiency (Ng, 2012). Lack of computer resources and lack of Internet access are the barriers suggested in digital divide research (NTIA, 1999; Van Deursen \& Van Dijk, 2019). Slow Internet is a new barrier emerged from our data. Two coders first developed the coding scheme and then coded a subset of the data sample together to discuss and refine the coding scheme. Together, the two researchers coded almost half of the sample, compared and discussed coding, and refined and finalized the coding scheme. Then, one coder followed the agreed coding scheme to complete coding of the remaining data. The inter-rater reliability of coding is satisfactory, with a Cohen's Kappa Index of 0.886, suggesting a high level of agreement between the two coders (Ryan \& Bernard, 2000).

Table 1. Demographic characteristics of the study participants $(n=206)$

\begin{tabular}{|c|c|c|}
\hline & Frequency & Percentage \\
\hline \multicolumn{3}{|l|}{ Gender } \\
\hline Female & 108 & $52.4 \%$ \\
\hline Male & 98 & $47.6 \%$ \\
\hline \multicolumn{3}{|l|}{ Employment Status } \\
\hline Not employed (Full-time Student Only) & 69 & $33.5 \%$ \\
\hline Employed full-time & 79 & $38.3 \%$ \\
\hline Employed part-time & 58 & $28.2 \%$ \\
\hline \multicolumn{3}{|l|}{ Household Income } \\
\hline Less than $\$ 20,000$ & 44 & $21.4 \%$ \\
\hline$\$ 20,000$ to $\$ 34,999$ & 42 & $20.4 \%$ \\
\hline$\$ 35,000$ to $\$ 49,999$ & 37 & $18.0 \%$ \\
\hline$\$ 50,000$ to $\$ 74,999$ & 36 & $17.5 \%$ \\
\hline$\$ 75,000$ to $\$ 99,999$ & 24 & $11.7 \%$ \\
\hline$\$ 100,000$ to $\$ 149,999$ & 14 & $6.8 \%$ \\
\hline$\$ 150,000$ or More & 9 & $4.4 \%$ \\
\hline \multicolumn{3}{|l|}{ Ethnicity } \\
\hline Hispanic or Latino & 123 & $59.7 \%$ \\
\hline Asian or Pacific Islander & 31 & $15.0 \%$ \\
\hline Black or African American & 24 & $11.7 \%$ \\
\hline White / Caucasian & 19 & $9.2 \%$ \\
\hline Others & 9 & $4.4 \%$ \\
\hline \multicolumn{3}{|l|}{ First-Generation College Student (FGCS) } \\
\hline FGCS & 127 & $61.7 \%$ \\
\hline Non-FGCS & 79 & $38.3 \%$ \\
\hline Grand Total & 206 & $100.0 \%$ \\
\hline
\end{tabular}


Table 2. Distribution of participants reporting digital barriers $(n=206)$

\begin{tabular}{|c|c|c|c|}
\hline & YES-Digital Barrier & NO-Digital Barrier & Total \\
\hline \multicolumn{4}{|l|}{ Gender } \\
\hline Female & $33.3 \%$ & $66.7 \%$ & $100 \%$ \\
\hline Male & $29.6 \%$ & $70.4 \%$ & $100 \%$ \\
\hline \multicolumn{4}{|l|}{ Employment Status } \\
\hline Not employed (Full-time Student Only) & $30.4 \%$ & $69.6 \%$ & $100 \%$ \\
\hline Employed full-time & $30.4 \%$ & $69.6 \%$ & $100 \%$ \\
\hline Employed part-time & $34.5 \%$ & $65.5 \%$ & $100 \%$ \\
\hline \multicolumn{4}{|l|}{ Household Income } \\
\hline Less than $\$ 20,000$ & $31.8 \%$ & $68.2 \%$ & $100 \%$ \\
\hline$\$ 20 \mathrm{k}-\$ 34,999$ & $42.9 \%$ & $57.1 \%$ & $100 \%$ \\
\hline$\$ 35 \mathrm{k}-\$ 49,999$ & $45.9 \%$ & $54.1 \%$ & $100 \%$ \\
\hline$\$ 50 \mathrm{k}-\$ 74,999$ & $13.9 \%$ & $86.1 \%$ & $100 \%$ \\
\hline$\$ 75 \mathrm{k}-\$ 99,999$ & $25.0 \%$ & $75.0 \%$ & $100 \%$ \\
\hline$\$ 100 \mathrm{k}-\$ 149,999$ & $21.4 \%$ & $78.6 \%$ & $100 \%$ \\
\hline$\$ 150,000$ or More & $22.2 \%$ & $77.8 \%$ & $100 \%$ \\
\hline \multicolumn{4}{|l|}{ Ethnicity } \\
\hline Asian or Pacific Islander & $41.9 \%$ & $58.1 \%$ & $100 \%$ \\
\hline Black or African American & $25.0 \%$ & $75.0 \%$ & $100 \%$ \\
\hline Hispanic or Latino & $29.3 \%$ & $70.7 \%$ & $100 \%$ \\
\hline White / Caucasian & $47.4 \%$ & $52.6 \%$ & $100 \%$ \\
\hline Others & $11.1 \%$ & $88.9 \%$ & $100 \%$ \\
\hline \multicolumn{4}{|l|}{ First-Generation College Student (FGCS) } \\
\hline FGCS & $28.3 \%$ & $71.7 \%$ & $100 \%$ \\
\hline Non-FGCS & $36.7 \%$ & $63.3 \%$ & $100 \%$ \\
\hline Grand Total & $31.6 \%$ & $68.4 \%$ & $100 \%$ \\
\hline
\end{tabular}

The coding result reveals that $31.6 \%$ of the respondents reported digital barriers when migrating to online platforms for all classes in the middle of 2020 spring semester. The distribution of study participants by digital barrier experience is summarized in Table 2.

\section{FINDINGS}

Our data analysis revealed five technical issues arising in online learning during COVID-19. The five digital barriers include slow Internet, technical problems, lack of computer resources, lack of Internet access, and skill deficiency.

\section{Digital Barrier 1: Slow Internet}

Slow Internet was the most frequently reported barrier by the survey respondents. It refers to the reduced Internet speed due to multiple users at the same time in a household. This barrier accounts 
for $67.7 \%$ of the reported digital barriers. This is not surprising as all family members were confined to their homes due to the "Shelter-in-place" order: they needed Internet to perform their jobs or take online classes, which negatively impacted the Internet speed. The slow Internet affected students' learning experience, as one respondent explained, "The biggest barrier is slow Internet, I live with 7 other people and since everyone is home at the same time everyone uses their devices at the same time and it conflicts with my learning." The situation worsened during the COVID-19 lockdown when the common public study places such as the university library or coffee shops were closed, which took away students' last option for free, fast Internet access.

\section{Digital Barrier 2: Technical Problems}

The second barrier is technical problems, accounting for $16.9 \%$ of the total digital barriers. Technical problems are associated with computer software, hardware, or network during online instructions (Muilenburg \& Berge, 2005). Students reported "Zoom glitches" or problems with video or audios. Sometimes, causes to a technical problem were not clear, as one student explained, "My computer sometimes exits out on me randomly. This has happened while taking exams or doing assignments." When technical problems occurred during their online learning, students could call the campus IT Helpdesk during regular office hours ( $9 \mathrm{am}-5 \mathrm{pm}$ ) or submit a troubleshooting ticket online anytime. However, given the variety of online class schedules and assignment submissions, students who took evening classes or worked on assignments during the weekend could not reach the IT Helpdesk when technical problems occurred. During those times, students became anxious about potential technical problems, as one elaborated, "One major barrier is relying on my computer and hope that it doesn't crash or that they system doesn't stop working while I am doing work."

\section{Digital Barrier 3: Lack of Computer Resources}

The third barrier is lack of sufficient computer resources, which accounted for $7.7 \%$ of the digital barriers. Insufficient resources of computer hardware and software are hindering student engagement in online learning. One such limitation is the incompatibility between outdated computer hardware at home and the latest software required by online learning platforms. Without access to computer labs and resources on campus, many students found themselves inadequately equipped at home to effectively participate in online learning. One respondent explained: "My kids are at home. They also have to do homework on the Internet. One computer is not enough. I just wish we have faster internet and another desktop or a laptop."

Some respondents reported lacking equipment such as a printer. During normal times, printing services were often provided at campus facilities. Due to campus shutdown, students lost an important learning aid, as one student explained, "I typically enjoy printing assignments and referring to them and without a printer it is more difficult to manage assignments."

\section{Digital Barrier 4: Lack of Internet Access}

A small percentage (4.6\%) of participants reported lacking Internet access. Students used to rely on smartphones for their occasional online learning needs at home but found it inadequate when using their phones to take online classes. This is elaborated by one student: "I worry about my internet access lasting during this time period because I do not have internet at home and instead use a mobile hotspot to work on homework and work materials."

Another reason is families' worsening financial situation. When family members lost jobs during COVID-19, students could not afford to pay for their Internet access. With limited financial resources, they would secure their shelter and food first before considering Internet service. A student expressed this worry: "Another problem is not being sure I'll have access to the internet for the rest of the semester since family is not working at the moment." 


\section{Digital Barrier 5: Skill Deficiency}

The last digital barrier is skill deficiency, i.e., insufficient knowledge or skills in using academic technologies such as Blackboard and videoconference tools such as Zoom ( $\mathrm{Ng}, 2012)$. Only 3.1\% of respondents experienced this barrier. One student, who worked full-time as a restaurant manager, explained the digital challenge for online learning during COVID-19, "It is very challenging having all classes online. I have other responsibilities to worry about, Also I am not fully known to Zoom so it is hard for me to understand how it works."

\section{DIFFERENCES IN DIGITAL BARRIERS BY STUDENT'S BACKGROUND}

Table 3 summarizes the distribution of digital barriers by demographic and socioeconomic background of the survey respondents. As shown, digital barriers are not evenly distributed across the respondents of different background. One major uneven distribution is that $75.4 \%$ of the digital barriers were reported by students with household income less than $\$ 50,000$. In this study, we consider families with income $\$ 50,000$ as low-income because $\$ 50,000$ is below the median household income level in the region where the university is located.

The problem of slow Internet is more prevalent among low-income students and minority students than their counterparts. This is consistent with a previous study that income is an important factor restricting broadband adoption and use at home; low-income families tend to be more smartphonedependent and lack access to multiple internet-enabled devices (e.g., tablets, PCs or laptops) (Anderson \& Kumar, 2019).

In terms of lacking computer resources, only females, minority students, and FGCS reported such barrier. That is, no male students, no White students, and no continuing-generation students (non-FGCS) reported lacking computer resources. These findings are mostly consistent with previous studies that female and underrepresented students are at a disadvantage in ICT access and usage (Anderson \& Kumar, 2019).

Technical problems and Internet connectivity seem to challenge all students. This can be partly explained by the high percentage of underserved students who are from low-income families and have minority ethnic background in our sample. As Van Dijk (2017) suggested, unequal distribution of resources leads to inequality of digital technological access, which in turn can lead to unequal participation in society that widens inequalities and distribution of resources.

\section{Individual Coping Behaviors}

Our supplemental analysis of the respondents' narratives revealed three common strategies for coping with digital barriers: improvising, building technical assets, and building social assets. We define coping as constantly changing one's cognitive and behavioral efforts to manage specific internal or external demands that exceed the resources of the person (Lazarus \& Folkman, 1984). The first strategy is improvising. In the online environment formed from COVID-19, we view improvisation as an individual act of finding alternative solutions to cope with the inadequacy in technology resources or deficiency in technical skills. An example of improvising acts of students for coping with slow Internet is that: "I have been having issues with my home internet for months. We have used extenders for the WiFi and some modifications to our modem." Another explained that:

There are 3 students in my home so our internet tends to be really slow while we are all doing our homework. I am trying to handle that barrier by having an assigned time we each get to work on our most important assignments in which we need faster internet and try to stay off the internet while the other one works on homework. 
Table 3. Distribution of the five types of digital barriers $(n=65)$

\begin{tabular}{|c|c|c|c|c|c|}
\hline & Slow Internet & $\begin{array}{l}\text { Technical } \\
\text { problems }\end{array}$ & $\begin{array}{l}\text { Lack computer } \\
\text { resources }\end{array}$ & $\begin{array}{l}\text { Lack internet } \\
\text { access }\end{array}$ & Skill deficiency \\
\hline All & $67.7 \%$ & $16.9 \%$ & $7.7 \%$ & $4.6 \%$ & $3.1 \%$ \\
\hline \multicolumn{6}{|c|}{ Gender $(0=$ Female; $1=$ Male $)$} \\
\hline 0 & $33.8 \%$ & $7.7 \%$ & $7.7 \%$ & $3.1 \%$ & $3.1 \%$ \\
\hline 1 & $33.8 \%$ & $9.2 \%$ & $0.0 \%$ & $1.5 \%$ & $0.0 \%$ \\
\hline \multicolumn{6}{|c|}{ Employment Status $(0=$ unemployed; 1 =full-time; 2 =part-time $)$} \\
\hline 0 & $21.5 \%$ & $9.2 \%$ & $1.5 \%$ & $0.0 \%$ & $0.0 \%$ \\
\hline 1 & $26.2 \%$ & $3.1 \%$ & $3.1 \%$ & $1.5 \%$ & $3.1 \%$ \\
\hline 2 & $20.0 \%$ & $4.6 \%$ & $3.1 \%$ & $3.1 \%$ & $0.0 \%$ \\
\hline \multicolumn{6}{|c|}{$\begin{array}{l}\text { Household Income } \\
(0=<\$ 20 \mathrm{k}, 1<=<35 \mathrm{k}, 2=<50 \mathrm{k}, 3=<75 \mathrm{k}, 4=<100 \mathrm{k}, 5=<150 \mathrm{k}, 6>=150 \mathrm{k})\end{array}$} \\
\hline 0 & $13.8 \%$ & $4.6 \%$ & $3.1 \%$ & $0.0 \%$ & $0.0 \%$ \\
\hline 1 & $18.5 \%$ & $6.2 \%$ & $1.5 \%$ & $1.5 \%$ & $0.0 \%$ \\
\hline 2 & $21.5 \%$ & $1.5 \%$ & $0.0 \%$ & $1.5 \%$ & $1.5 \%$ \\
\hline 3 & $4.6 \%$ & $1.5 \%$ & $1.5 \%$ & $0.0 \%$ & $0.0 \%$ \\
\hline 4 & $4.6 \%$ & $1.5 \%$ & $1.5 \%$ & $1.5 \%$ & $0.0 \%$ \\
\hline 5 & $1.5 \%$ & $1.5 \%$ & $0.0 \%$ & $0.0 \%$ & $1.5 \%$ \\
\hline 6 & $3.1 \%$ & $0.0 \%$ & $0.0 \%$ & $0.0 \%$ & $0.0 \%$ \\
\hline \multicolumn{6}{|c|}{ Ethnicity (1=Asian; 2=African American; 3=Hispanic; 4=White;5=others } \\
\hline 1 & $16.9 \%$ & $1.5 \%$ & $1.5 \%$ & $0.0 \%$ & $0.0 \%$ \\
\hline 2 & $3.1 \%$ & $3.1 \%$ & $3.1 \%$ & $0.0 \%$ & $0.0 \%$ \\
\hline 3 & $38.5 \%$ & $7.7 \%$ & $3.1 \%$ & $4.6 \%$ & $1.5 \%$ \\
\hline 4 & $7.7 \%$ & $4.6 \%$ & $0.0 \%$ & $0.0 \%$ & $1.5 \%$ \\
\hline 5 & $1.5 \%$ & $0.0 \%$ & $0.0 \%$ & $0.0 \%$ & $0.0 \%$ \\
\hline \multicolumn{6}{|c|}{ First-Generation College Student } \\
\hline YES & $33.8 \%$ & $9.2 \%$ & $7.7 \%$ & $3.1 \%$ & $1.5 \%$ \\
\hline NO & $33.8 \%$ & $7.7 \%$ & $0.0 \%$ & $1.5 \%$ & $1.5 \%$ \\
\hline
\end{tabular}

In both cases, students faced the technical barriers of slow Internet, so they made some modifications in their equipment (such as using a WiFi extender) or in their study routines in the household (assigning Internet access time). However, when they had no Internet access or unstable Internet, students looked for alternatives. Two workaround solutions are shown as: "I don't have internet connection at home so I have to be using my mobile hotspot to connect with my computer." "My biggest challenge is problems with the internet connection. I try not to complete tasks last minute in case blackboard is down or my internet is not working."

In these cases, students used their iPhone hotspot for network connection and modified their study schedules (such as submitting tasks prior to a deadline) to overcome the challenges caused by technology deficiency. When students attempted to maximize their existing technology resources, they were adopting the improvising strategy. 
The second strategy is building technical assets by purchasing new computers or loaning one from university. This strategy is demonstrated in a student response: "My biggest barriers are slow Internet and lack of study space. I have invested in fixing my computer and upgrading my internet support." Another student elaborated:

I do have a laptop unfortunate it is old and unable to download the recent programs required for my assignments. It would be of good help if the university came up with a way to grant me a loan laptop with the software required to finish my assignment.

The technical assets above resemble the technical capital described in Bourdieu's Capital Theory (1986; 2002): capital can present itself in five forms - economic, cultural, social, symbolic and technical - and each form of capital is essential to a society's economic growth. As one of the forms, technical capital captures the technological resources and technology-related skills that a person develops using computing equipment.

The third strategy is building social assets. This is similar to Bourdieu's (1986; 2002) description of social capital that consists of social obligations or connections. In a study of Latino middle-school students, social support was found positively associated with students' school competencies in adverse situations (Crean, 2004). Although this strategy is less common in our sample, it is worth noting that some students reached out to their classmates and friends to resolve some technical issues and gain knowledge about using academic technologies such as video call services. In a reflection of coping for skill deficiency, one respondent noted that "A lot of students had never done an online class before and don't know how to navigate on video call services. Better forums for students to talk to. IE: Reddit, instagram or facebook?"

Individuals accumulate experiences in confronting and overcoming resource challenges. Prior research has suggested that individuals who are used to facing challenges for prolonged periods of time acquire skills that assist them in coping with new challenges (Seery et al., 2010). These skills help them cope with existing and recurring situations of adversity, for example, among FGCS (Garriott \& Nisle, 2018; Gloria \& Castellanos, 2012). Our study shows that FGCS utilized their skills and capabilities to cope with challenges of lacking technology resources.

\section{DISCUSSION}

COVID-19 has diminished some benefits of distance education such as the flexibility of taking online classes anywhere and anytime. During COVID-19, students were confined in their homes, experiencing slow network and inadequate computing resources required for distance education. In addition to their academic work, many students struggled with multiple roles, managing demands from their employment (such as essential workers), their family responsibilities of childcare, homeschooling their children, or elderly care. Our study suggested that digital barriers distributed unevenly among students with different household income, gender, ethnicity, and FGCS status. COVID-19 has brought unprecedented digital challenges to the underserved college students, hindering their academic success on the online platforms.

\section{CONTRIBUTION TO RESEARCH}

This study contributes to the research on digital divide by examining and uncovering the nuances of digital barriers in online learning. As van Dijk (2006) indicated, digital divide research suffers from a lack of theory. By revealing the nuances of technical barriers, our study suggests that capital theory could be a useful lens for further investigating the digital divide and digital inclusion in online learning. 
In addition, the study extends research on the coping behaviors of FGCS by revealing their coping strategies in relation to digital barriers. Improvising is related to modifying existing online learning environment and changing daily study routines. This strategy is unique to the technologyrelated challenges in distance education. The other two strategies are building social and technology assets. Social assets include family support and connections with university staff, peers, and faculty. Prior study on Latino students found that involving families within the education process, such as facilitating their connections with schoolmates and university personnel, is critical for the success of Latino FGCS (Gloria \& Castellanos, 2012). Furthermore, institutional support plays an important role in mediating the effect that stress has on perceived academic progress for FGCS (Garriott \& Nisle, 2018).

Although students from low-income households without sufficient Internet access had attempted to find workaround solutions, they were disadvantaged in their academic progress compared to their peers. This phenomenon is referred to as the "homework gap": low-income students who lack online access lag behind their higher-income counterparts when completing assignments and other school-related activities (Lee, 2020). The homework gap was widened during the pandemic because low-income students could not use public WiFi as they used to. During COVID-19 when in-person instructions were disrupted, lacking adequate ICT resources and skills created digital barriers for low-income students' online learning. These barriers have prevented them from effectively accessing information and acquiring knowledge, which are essential building blocks of the knowledge pyramid (Jennex, 2017).

\section{CONTRIBUTION TO PRACTICES}

Students' digital inclusion can help mitigate the economic disadvantages and lack of parental support for working-class students. This initiative is especially important for promoting the digital competence of students from diverse social, economic, and ethnical backgrounds. Our study highlights that, for educational institutions to prepare students for success in academic study and future career, the institutions need to design and implement programs to overcome students' digital barriers and to enhance their digital inclusion in the online space. To help online students resolve technical problems and become more engaged in online learning, our study suggests the following equity-minded practices.

First, to address the barriers of slow or no Internet, higher educational institutions should mobilize school resources and provide mobile Internet services to students, especially low-income students. In addition, support by and involvement of private and public sectors are important. In the short term, private sectors have started to make efforts in response to COVID-19. For example, Internet service providers such as Verizon voluntarily pledged to limit fees, forgive fines, and remove data caps in the spring of 2020 (Frazier, 2020). However, to achieve academic continuity in distance education for the long term, government involvement is needed.

Second, to address the barriers of technical problems and lacking computer resources or skills, educational institutions should consider: (1) implementing a tech loaner program that provides students, especially low-income, minority, and FGCS with free laptop computers and updated software that are sufficient for their online class needs; (2) providing students with self-paced training on online learning platforms; (3) extending the office hours of IT Help Desk to accommodate evening and weekend classes; and (4) reducing response time of the IT Help Desk.

Finally, to improve community focus and diversity awareness, institutions should (1) set up communication norms between instructors and students at the beginning of online classes (i.e., such as expected time to return an email); (2) offer sufficient opportunities for students to schedule Zoom meetings with instructors; and (3) create assignments on understanding how the COVID-19 crisis affects underserved communities. 


\section{CONCLUSION}

Inequalities within society have always existed, but distance education in the times of crisis created an even stronger division. Our study further suggested that demographics and socioeconomic status should be considered when examining learners' technology access, use, and proficiency in the online learning environment. As stated in a recent published book, even free to access, learning technologies often provide the greatest benefit to affluent students and do little to combat growing inequality in education (Reich, 2020). To some extent, COVID-19 has expanded the digital divide in distance education. Educational institutions and policymakers should consider designing and implementing intervention programs focusing on improving resource access and developing the digital skills essential for students from underserved communities to achieve their academic goals during COVID-19 and beyond.

The study has several limitations. First, it used a convenience sample, collected from a public university located in a metropolitan area in the U.S. Therefore, findings of the study may not be applicable to universities in other regions. Second, the survey was conducted during the first two weeks of transition to distance learning. As student learning experience could have changed after this specific window of time, it would be helpful for future research to employ more advanced sampling strategies and conduct a longitudinal study to measure student performance in the face of digital barriers arising from distance education.

In the long term, digital skills acquired from higher education have become one success factor in the professional workplace. For college graduates to succeed in today's digital society, it is important for them to embrace the latest technologies and acquire advanced knowledge such as Big Data, data analytics, and even artificial intelligence (Jennex, 2017). In this regard, overcoming major digital barriers in higher education has become a purposeful and critical step towards students' future career success.

\section{ACKNOWLEDGMENT}

This paper was originally presented at HICSS-54 in the Track "Knowledge, Innovation, and Entrepreneurial Systems." The original paper title was "Digital Divide and Digital Barriers in Distance Education during COVID-19.” The extension from the HICSS paper includes a new section (Individual Coping Behaviors), revised introduction, and expanded discussion. We also modified the research questions and paper title to include coping behaviors in the face of digital barriers in COVID-19. 


\section{REFERENCES}

Alavi, M., \& Leidner, D. E. (2001). Knowledge management and knowledge management systems: Conceptual foundations and research issues. Management Information Systems Quarterly, 25(1), $107-136$. doi: $10.2307 / 3250961$

Anderson, M., \& Kumar, M. (2019, May 7). Digital divide persists even as lower-income Americans make gains in tech adoption. Pew Research Center Report. https:/www.pewresearch.org/fact-tank/2019/05/07/digital-dividepersists-even-as-lower-income-americans-make-gains-in-tech-adoption/

Bourdieu, P. (1986). The forms of capital. In J. Richardson (Ed.), Handbook of theory and research for the sociology of education (pp. 241-258). Greenwood.

Bourdieu, P. (2002). The social structure of the economy. Polity.

Cho, S. K., \& Berge, Z. L. (2002). Overcoming barriers to distance training and education. USDLA Journal, 16(1), 16-34.

Crean, H. F. (2004). Social support, conflict, major life stressors, and adaptive coping strategies in Latino middle school students: An integrative model. Journal of Adolescent Research, 19(6), 657-676. doi:10.1177/0743558403260018

Cruz-Jesus, F., Vicente, M. R., Bacao, F., \& Oliveira, T. (2016). The education-related digital divide: An analysis for the EU-28. Computers in Human Behavior, 56, 72-82. doi:10.1016/j.chb.2015.11.027

Frazier, K. (2020, July 9). The coronavirus pandemic is expanding California's digital divide. Tech Crunch. https://techcrunch.com/2020/07/09/the-coronavirus-pandemic-is-expanding-californias-digital-divide/

Garriott, P. O., \& Nisle, S. (2018). Stress, coping, and perceived academic goal progress in first-generation college students: The role of institutional supports. Journal of Diversity in Higher Education, 11(4), 436-450. doi: $10.1037 /$ dhe0000068

Gloria, A. M., \& Castellanos, J. (2012). Desafíos y bendiciones: A multiperspective examination of the educational experiences and coping responses of first-generation college Latina students. Journal of Hispanic Higher Education, 11(1), 82-99. doi:10.1177/1538192711430382

Grand-Clement, S. (2017). Digital learning: Education and skills in the digital age. Rand Corporation. doi:10.7249/CF369

Jennex, M. E. (2017). Big data, the internet of things, and the revised knowledge pyramid. ACM SIGMIS Database: the DATABASE for Advances in Information Systems, 48(4), 69-79. doi:10.1145/3158421.3158427

Jennex, M. E., \& Bartczak, S. E. (2013). A revised knowledge pyramid. International Journal of Knowledge Management, 9(3), 19-30. doi:10.4018/ijkm.2013070102

Jones, S., Johnson-Yale, C., Millermaier, S., \& Pérez, F. S. (2009). US college students' Internet use: Race, gender and digital divides. Journal of Computer-Mediated Communication, 14(2), 244-264. doi:10.1111/j.10836101.2009.01439.x

Kim, K. J., Bonk, C. J., \& Oh, E. (2008). The present and future state of blended learning in workplace learning settings in the United States. Performance Improvement, 47(8), 5-16. doi:10.1002/pfi.20018

Lauff, E., \& Ingels, S. J. (2015). Education longitudinal study of 2002 (ELS: 2002): A first look at the postsecondary transcripts of 2002 high school sophomores (NCES 2015-034). US Department of Education, National Center for Education Statistics.

Lazarus, R. S., \& Folkman, S. (1984). Stress, appraisal, and coping. Springer.

Lee, N. T. (2020). What the coronavirus reveals about the digital divide between schools and communities. Brookings Institute. https://www.brookings.edu/blog/techtank/2020/03/17/what-the-coronavirus-reveals-aboutthe-digital-divide-between-schools-and-communities/

Miles, M. B., \& Huberman, A. M. (1996). Qualitative data analysis: An expanded sourcebook. Sage (Atlanta, Ga.). 
Muilenburg, L. Y., \& Berge, Z. L. (2001). Barriers to distance education: A factor analytic study. American Journal of Distance Education, 11(2), 39-54. doi:10.1080/08923640109527081

Muilenburg, L. Y., \& Berge, Z. L. (2005). Student barriers to online learning: A factor analytic study. Distance Education, 26(1), 29-48. doi:10.1080/01587910500081269

Ng, W. (2012). Can we teach digital natives digital literacy? Computers \& Education, 59(3), 1065-1078. doi:10.1016/j.compedu.2012.04.016

Notley, T. (2009). Young people, online networks, and social inclusion. Journal of Computer-Mediated Communication, 14(4), 1208-1227. doi:10.1111/j.1083-6101.2009.01487.x

NTIA. (1999). Falling through the net: Defining the digital divide. United States Department of Commerce. https://www.ntia.doc.gov/report/1999/falling-through-net-defining-digital-divide

Reich, J. (2020). Failure to disrupt: Why technology alone can't transform education. Harvard University Press. doi:10.4159/9780674249684

Ryan, G. W., \& Bernard, H. R. (2000). Techniques to identify themes in qualitative data: Handbook of qualitative research (2nd ed.). Sage Publications.

Safford, K., \& Stinton, J. (2016). Barriers to blended digital distance vocational learning for non-traditional students. British Journal of Educational Technology, 47(1), 135-150. doi:10.1111/bjet.12222

Schwartz, S. E., Kanchewa, S. S., Rhodes, J. E., Gowdy, G., Stark, A. M., Horn, J. P., \& Spencer, R. (2018). I'm having a little struggle with this, can you help me out?': Examining impacts and processes of a social capital intervention for first-generation college students. American Journal of Community Psychology, 61(1-2), 166-178. doi:10.1002/ajcp.12206 PMID:29178300

Van Deursen, A. J., \& Van Dijk, J. A. (2019). The first-level digital divide shifts from inequalities in physical access to inequalities in material access. New Media \& Society, 21(2), 354-375. doi:10.1177/1461444818797082 PMID:30886536 


\section{APPENDIX: SURVEY QUESTIONNAIRE}

1. What is your gender? Male / Female / Gender Non-Conforming

2. What is your age?

3. Are you a first-generation student (first in your family to go to a 4-year university)? YES / NO

4. What is your major at the University?

5. What is your year in school? Freshman, Sophomore, Junior, Senior, Graduate

6. What is your zipcode (where you live)?

7. How concerned are you about the coronavirus (COVID-19) spread in the U.S. now? (Not concerned at all; somewhat concerned; concerned; very much concerned)

8. Do you have a computer at home? YES/NO

9. Do you have Internet Access at home for using the CSUDH Blackboard? YES/NO

10. Please rate your proficiency with using information and communication technology tools on a scale of 1-4 with 1 being "Not Proficient" and 4 being "Very Proficient":

a. Web-based course management system, e.g., Blackboard.

b. Internet video and audio call services, e.g., Zoom, Skype.

11. What are the major barriers for you to continue the college classes via the alternative instruction mode (such as distance learning) during the remaining weeks of the semester? Please explain.

12. What services and support do you wish that University will provide you to maintain the continuity of your academic study at the University during the evolving circumstance of coronavirus spread? Please explain.

13. Are you currently part-time or full-time employed? (Yes-employed full-time; Yes—employed part-time; No-Student Only)

14. If you reply "YES" above (on employment status), then where do you work and what is your job title? (If you reply "No" above, just type "NA" in the comment box.)

15. If you reply "YES" above (on employment status), what has your employer done to protect the health and safety of you during the COVID-19 outbreak (such as flexible work hours, working from home, etc)? (If you reply "No" above, just type "NA" in the comment box.)

16. What is your marriage status? (use the suggested list recommended by Survey Monkey)

17. What caregiving responsibilities do you have at home? (none; taking care of my children; taking care of my elderly parent; taking care of grandparents; others-please explain)

18. What is your ethnic background? (Select All that Apply) (use the suggested list recommended by Survey Monkey)

19. What is your estimated household income? (use the suggested list recommended by Survey Monkey)

20. You are also welcome to put here any additional comments you might have. Thank You for your timely and valuable input.

Isabel Gan attends Thomas Jefferson High School for Science and Technology located in Alexandria, Virginia, USA. Her research interests include gender equality in STEM, digital divide in online education, and ethical issues in Artificial Intelligence applications. She has presented her research work at the 2020 INFORMS Conference and has presented and published her research at HICSS-54.

Rui Sun is a tenured Associate Professor in the Department of Public Administration, California State University, Dominguez Hills, California, USA. She received her Ph.D. in Policy Studies from the University of Maryland. Dr. Sun's research focuses on government budgeting, public and nonprofit financial management, and social media utilization in nonprofit organizations. 